\title{
DIGITALIZATION OF THE AWARDING PROCESS IN BULGARIA DURING A PANDEMIC
}

\author{
Miglena Pavlova ${ }^{1}$ \\ e-mail:mpavlova@unwe.bg;m.pavlova@aop.bg
}

\begin{abstract}
The spread of COVID-19 in the past year has posed a serious challenge to state economies. The pandemic had an impact on the management and economy of developing countries and transition countries, which required the reorganization of management methods and increased use of information and communication technologies in everyday life. This complex and unexpected environment has altered the way the public administration works, which reflects on the business as well. Bulgaria was not isolated from the effect and took measures, including legislative measures to deal with the situation. In parallel with these processes, a serious reform in the "Public Procurement" sector was carried out in Bulgaria related to the digitalization of the awarding process. Digitalization has led to streamlining the process of conducting public procurement procedures and has enabled its effectiveness to be improved.
\end{abstract}

Key words: electronic procurement, public services, public procurement, electronic platform for the award process, procurement awarding

JEL: H4, H57, H570

\section{Introduction}

Modern information and communication technologies (ICT) are the main driver of change in the governance, economies and societies of each country. The development of ICT opens up a wide range of opportunities to improve processes within and between organizations. Following the lessons of the private sector, public authorities and public administration in general also turn to ICT in search of efficiency and effectiveness. The phasing-in of e-procurement is part of the European Union's (EU) ambitious e-Governance Plan, which aims to fully transform the activities of public administration and achieve better results, respectively. High quality public services are largely dependent on modern, well-managed and efficient public procurement. Annually, around 14\% of the GDP (about EUR 2 trillion per year) of the EU is spent under public procurement contracts. According to a survey by the European Commission (EC), even a $1 \%$ increase in

\footnotetext{
${ }^{1}$ Assoc. Prof., PhD, Department of Financial Control, Faculty of Finance and Accounting, University of National and World Economy
} 
efficiency in the sector could save 20 billion euros a year (European Commission, n. d.). In other words, the public procurement market spends a serious public resource and the digitalization of the sector allows this to become an efficient and effective way by saving time and resources and in the same time increases the publicity and transparency of the processes.

Except a means of satisfying a certain public interest, public procurement is an important instrument for ensuring the protection of this public interest when spending public funds and complying with the principles of the TFEU. They are an important incentive for economic activity, an instrument to increase the competitiveness of the European market, as well as a means of ensuring economic growth. Given the importance of the public procurement sector, its digital transformation is a priority on the agenda of the EU institutions. Thus, as early as 1998, the Commission called on the Member States to stimulate "a common European electronic procurement environment", in which $25 \%$ of the orders are carried out electronically. The legislative measures taken in 2004, known as the 2004 Directives (Directive 2004/18/EC and Directive 2004/17/EC) and later those of 2014 (Directive 2014/24/EU and Directive 2014/25/EU) in the field of public procurement, accompanied by a number of policy-backing initiatives, aim at achieving the best conditions for spending public funds through the digitalization of public procurement and also increasing the publicity, transparency and predictability of the contracting process.

Electronic procurement that is carried out automated and in real time leads to strengthening both the transparency and efficiency of the process. They reduce bureaucracy and administrative burdens, provide significant savings for all countries, offer simplified and shortened processes, and contribute to a more competitive and fair environment in which everything happens at the moment. Their digitalization opens new business opportunities by the access of enterprises, including small and medium-sized enterprises (SMEs) to public procurement markets. More transparent digitalized award procedures have a higher value against the funds invested in their creation, as they create economies of scale. Last but not least, the digitalization of the public procurement cycle implies better data management and decision-making capability based on data.

In 2014, the Commission presented a whole new package of directives in the field of public procurement - Directive 2014/24/EU of the European Parliament and of the Council of 26 February 2014 on public procurement and repealing Directive 2004/18/EC and Directive 2014/25/EU of the European Parliament and of the Council of 26 February 2014 on the award of contracts by entities operating in the water, energy, transport and postal services sectors and repealing Directive 2004/17/EC. They aimed at simplifying procedural rules, unifying practice, facilitating cross-border transactions, and ensuring a smooth transition to fully electronic communication in the award process. Under the provisions of 
the Directives, each Member State should digitalize the processes from start-up to the possibility of submitting tenders, and in addition to provide full and free of charge electronic access to the procurement documents. The provisions of the Directives also entail the possibility of using electronic procurement techniques and tools such as electronic auction, electronic catalogues, electronic certificates and applicants' records, dynamic purchasing systems, and linking existing centralized procurement platforms.

Regarding the choice of electronic means, i.e. information solutions to be applied for the implementation of electronic procurement, the requirement is to respect the principles of accessibility and interoperability. The introduction of electronic means should not impede contracting entities and participants in the process by requiring the purchase of certain technical means or the use of specific electronic formats. At the same time, it is necessary to establish a link with other systems and registers, and any action of legal significance should be time stamped with a qualified electronic print. Access policies should also be drawn up, along with a detailed systemic history. Like any electronic system, for the public procurement as well it is necessary to respect basic principles such as traceability, security and proportionality (Pavlova, 2015). Traceability is provided in the information system by keeping information on all important consumer decisions and actions in system history. The electronic systems through which the contracting process is carried out are much more protected than unregulated access, distortion or loss of information from the traditional "material" way. This is due to high standards in the information society, consisting of law-protected information (personal data, production or trade secrets, classified information, etc.), as well as information security, seen as a set of measures and means to overcome threats, vulnerabilities, weaknesses and losses from unauthorized access to or unsanctioned loss of a particular type of information. The proportionality of the system implies a balance between user convenience and information security and prevention of corrupt practices.

In order to meet the requirements of the European Directives, Bulgaria carried out a study on the types of electronic procurement model in other EU Member States. As a result, reports have been prepared from the study of two different award models, given as good examples by the Commission. These are the models of Cyprus and Portugal. A central platform with unified business processes operates in Cyprus, which is managed by a government authority - the Public Procurement Directorate of the State Treasury (Ministry of Finance), while in Portugal several central public procurement bodies (CPBs) are available and also a multi-platform system based on a framework agreement with providers of electronic procurement platforms (Pavlova, 2015). 
In response to the study carried out, the good experience acquired and the requirement introduced by the 2014 Directives on the introduction of electronic communication in the process of awarding and the same time including submitting electronic offer, the Council of Ministers of the Republic of Bulgaria decided to choose a model of platform for electronic procurement. The selected model is a centralized one-platform one to be realized by acquiring a single electronic platform and integrating existing electronic procurement systems owned and used by central public procurement bodies (Council Decision No 108/19.02.2015). In addition, in the National Strategy for Development of the Public Procurement Sector in Bulgaria for the period 2014 - 2020 and its Implementation Plan have laid down a measure for development of centralized public procurement bodies, which should be integrated into the future national platform for electronic award.

As EU policy seeks to introduce a comprehensive electronic procurement cycle, this implies the introduction of electronic processes to maintain the different stages of the contracting process. Actions of publication of the contract notice, submission of the procurement documents, submission of tenders, evaluation, conclusion and management of the contract, invoicing up to payment are envisaged. With the development and commissioning of the national platform for electronic procurement in Bulgaria, the aim is to meet these requirements, as well as to achieve full digitalization of the entire contracting cycle.

\section{Bulgarian e-procurement platform - a comprehensive electronic cycle of public procurement}

The Roadmap for the Implementation of the Strategy for Development of eGovernment in the Republic of Bulgaria for the period 2014 - 2020 approved the construction of a Centralized Automated Information System "Electronic Public Procurement" (CAIS EPP). The construction and implementation of the system is the result of the project BG05SFOP001-1.003-0002-C01 "Development, implementation and maintenance of a single national electronic web-based platform: Centralized Automated Information System "Electronic Public Procurement" (CAIS EPP) funded under the Operational Program "Good Governance" 2014 -2020 and is a consequence of a public procurement procedure by the Public Procurement Agency (PPA).

Due to its complexity, the system was built on a modular basis in two launch stages until the end of 2020. 32 modules are provided. The first stage covers 16 modules or all the basic functionalities necessary to implement the contracting process as well as to fulfil the requirements of the European Directives in the field (Directive 2014/24/EU, Directive 2014/25/EU, Directive 2014/55/EU and Directive 2009/81/EC). The modules included in Stage I provide basic function- 
ality for electronic announcement, electronic communication in the course of the contracting process, submission of an electronic offer and issuing and accepting an electronic invoice. The second stage is upgraded and includes an additional 16 modules, which closes the entire contracting cycle.

An important feature in the construction of the system is the introduction into real operation even before the finalization of the latest functionalities and modules. In other words, it is alive and continues to develop and build up alongside its use by consumers. This provides a prerequisite for a more flexible and smooth transition to the new digital reality in the sector of all stakeholders. Smooth and appropriate adaptation in daily practice is ensured by the gradual introduction of the obligation to use the platform. The Public Procurement Law (PPL) regulates an obligation to use the national electronic platform by the contracting entities effective as of 1 January 2020 and by virtue of Decree No 332 of 13 December 2019 of the Council of Ministers a timetable has been adopted, which regulates the mandatory application of the system in stages. It is initially applied by contracting entities with a higher annual average of public procurement and budgets and later, from 14 June 2020, to all other contracting entities.

The system is used by all contracting entities in the country (both public and sectoral) and business entities, and the services are provided to consumers 24 hours a day, 7 days a week.

At the beginning of 2019 the modules E-Registration, E-Notification, E-Sender, E-Documentation, ESPD, Information Exchange in the course of the procedure, E-Submission, Opening of offers and applications for participation, E-Catalog, Conducting internal competitive choice under FA, Reports and statistical reports, E-Invoicing, as well as 4 service modules for the needs of PPA, which are used for business processes management and support the administration of the system were put into operation.

Module "e-Registration" (E- Registration) allows the registration of users of the system, which are generally three types - contracting entities, economic entities - legal and natural persons. A qualified electronic signature (QES) is required for successful registration. Consumer QES requirements are in accordance with Regulation (EU) 910/2014 on the electronic identification and certification services in electronic transactions in the internal market. This requirement is very important in relation to the authentication of the authorship of any document and any information presented through the system.

The e-Notification module provides the opportunity to announce public procurement procedures through the system. Contracting entities are given the opportunity to send notices directly to the Official Journal of the European Union (OJ) via the E-Sender service. The functionality of the system automatically generates all notices to be published in the EU's OJ and the Public Procurement 
Registry (PPR). CAIS EPP shall monitor the status of each notice sent and shall automatically carry out the national publication within the statutory deadlines. The system also announces low-value contracts such as collecting tenders with an advertisement and an invitation to certain persons. Contracting entities shall define the parameters of the contract in a structured form, allowing for a large part of the information in the applicable forms of notices and decisions to be completed automatically. This functionality saves contracting entities the need to reintroduce the same data, which improves working time and significantly reduces the risk of making technical errors. CAIS EPP shall apply certain rules for the validation of the completed information and warn if they are breached.

CAIS EPP provides the possibility to attach the complete documentation of a public procurement procedure, which effectively implements the e-Documentation Module.

In addition to the work of the contracting entities, the system shall also facilitate that of the other participants in the contracting process. All interested parties have the opportunity to review and download the participation documents for the published in the PPR orders. It should be noted here that access to the PPR does not require registration and everyone, even an unregistered user, has full, unlimited and free access to the published information. CAIS EPP is a single point for access to information on all procurement procedures, including low-value contracts, and the use of award techniques in the country. This significantly increases the access to information of all business entities.

The Information Exchange module provides the opportunity to generate and exchange messages between the contracting entity and all interested parties who have added the order to their user profile. The messages shall be retained in the record of the specific procurement. The whole process of exchanging information between the participants in the award process shall be carried out entirely electronically, including requesting clarification of the procurement documents, requests by the evaluation committees for clarification, submission of evidence and documents by candidates/participants in the course of the procedure, replies to them, etc. There is possibility of preparing and sending invitations to all economic operators who added the order when or necessarily. The system generates and sends automatic notifications when certain events occur, e.g. when publishing external control opinions, date and time for decryption of applications/offers, when changing the status of requests under contracts, etc.

As required by Directive 2014/55/EU of the European Parliament and of the Council of 16 April 2014 on e-invoicing in public procurement, the e-Invoice module has been implemented in the system. With the availability of this module, business operators may prepare invoices, credit and debit notifications under contracts concluded in the system and forward them to the contracting entities. 
Contracting entities shall, for their part, be able to accept and process the invoices received. The template of the invoice entered in the CAIS EPP requires the completion of data in a structured form and meets international standards in the field.

At the end of 2019, the EU announced that each country should itself provide the Single European Public Procurement Document (ESPD). This requirement is met in Bulgaria with the development of module e-ESPD. Users of CAIS EPP, contracting entities and economic operators, are given the opportunity to create and complete the ESPD in the system. If necessary, users may edit or reuse the document already created and completed in the CAIS EPP by downloading it in $\mathrm{html}$. format and using the System for filling out and reusing the ESPD, available on the Public Procurement Portal.

Business entities shall have the opportunity to prepare and submit their requests to participate and tenders through the E-Submission module. In order to ensure security and confidence in the system in preparing and submitting a bid, the development of CAIS EPP shall take into account the need for simplicity of the implementation and security of sensitive information. Taking into account the high sensitivity of society in terms of spending of public resources, as well as some cases of illegal practices in the field, the design of the system focuses on information security. Tenders shall be submitted electronically. The system supports algorithms for generating encryption keys and ensures the secure storage of the received offers until they are opened. Until the expiry date for opening the application/offer, it shall be contained in databases only in encrypted form. Business operators need to carry out additional action to provide the decryption key. The technical separation of encrypted offers and the keys to their decryption can be taken as a secure way of ensuring confidentiality and eliminating threats of unauthorized access and the danger of vicious practices.

With the implementation of module E-Catalogue it allows contracting entities to create electronic catalogues when preparing their contracts. These are documents with structured information on goods, services or works that participants may update and send as part of their tenders. The catalogue is an electronic format for the presentation and organization of information in a similar manner, the same for all participants in the procedure, which allows for subsequent electronic processing of the data. Automation implies rapid processing and evaluation of offers - objectivity and transparency is achieved, while good standardization saves effort and time.

The other modules of Stage I provide the opportunity for AOP staff to carry out the monitoring activities, review of information, generation of reports and statistical reports, maintenance of lists, etc.

The implemented modules of the second stage of CAIS EPP are distinguished from the mandatory modules set out in the Directives. The modules of Stage II 
can be divided into several main groups - procurement techniques ("Dynamic Purchasing System (DPS)", "Qualification System (QS)" and "e-Auction"), modules related to increasing publicity and supporting the work of authorities with functions in the field of public procurement ("External control, carried out by PPA”, „Ex-post control”, "External experts”, "Buyers Profile”, PPA webpage, "E-Appeal") and upgrading ("E-Shop", "E-Contract Request", "E-Needs Planning", "E-Selection", "E-Evaluation", "E-Awarding and Managing Contracts", "E-Payment").

With the transposition of the 2014 directives, a strong emphasis was given to electronic techniques and award tools. Among them are the electronic catalogue, the dynamic purchasing system and the electronic auction.

The introduction of CAIS EPP provides contracting entities in Bulgaria the opportunity of using a Dynamic Purchasing System. Given its nature of a fully electronic process, the DPS has not been used so far by the Bulgarian contracting entities (for more information see Pavlova, 2020, p. 109-119). Unlike the Qualification System, which benefits only from sectoral contracting entities, the DPS is also applicable to the public ones. Among the advantages of this electronic selection technique are the significant reduction of the deadlines for the purchases, the economic efficiency caused by the ensured broad competitiveness and minimized administrative costs, the expanded opportunities for participation of SMEs in the public procurement market, etc.

The other fully electronic instrument available to the contracting entities is the electronic auction carried out by means of the E-Auction module. This is an electronic process that starts after an initial overall evaluation of tenders and allows them to be ranked using methods for automatically assessing the new, lower prices and/or new values submitted in the tenders, affecting certain elements of the tenders. When conducting an electronic auction, the aim is to achieve the best price, or to improve values of the characteristics of the tenders in advance. Electronic auctions have obvious advantages in terms of time reduction, transaction costs, administrative burden and transparency. The last one is related to the real-time bidding.

The upgrade module in CAIS EPP is "E-Shop". Like the presented techniques and tools, this is an entirely electronic process of buying and selling goods and services below the threshold values of art. 20, para. 4 and 5 of the Public Procurement Law. The module allows users registered in the system to enter information on offered goods and services in a structured, predefined form, while contracting entities quickly and easily search for goods and services in catalogues, to create documents with requirements, to make comparisons in a set of parameters for goods or services for similar purposes, to request availability and to make requests.

As has already been pointed out, the purpose of the introduction of CAIS EPP is to complete the digitalization of the public procurement cycle. An important 
and complex stage of this cycle is planning. The "E-Planning" module provides an opportunity for contracting entities to plan and summarize their needs in the system. To facilitate users, the system maintains schedules of procurements in the form of a calendar. Events with automatic reminders can be added to the calendar. This functionality is of particular importance for Central Purchasing Bodies, as well as for large contracting entities with units, which collect and summarize the needs of individual units and create contracts based on planned needs. The introduction of the electronic award undeniably provides more opportunities to plan the award process, follow-up of contracts and follow-up until the conclusion of a specific procedure. The attempt to digitalize the entire contracting process - from the preparation and planning phase to ex-post controls, in practice ensures the achievement of findings on the need to take measures to increase transparency in the sector, as referred to in the "Report for Bulgaria for 2019, including in-depth review on the prevention and correction of macroeconomic imbalances" (European Commission, 2019, p. 71-73).

The "E-Selection" and "E-Evaluation" modules allow contracting entities to define and record a methodology for the evaluation of tenders, as well as to select candidates/participants and assess the tenders in the system. The functionalities of the modules allow the commission for consideration of tenders, evaluation and ranking to carry out its work entirely electronically, providing the instruments for completion of the procedure - preparation of protocols, reports, information on communication between the contracting entity and the commission in relation to the reception and validation actions, as well as generation of decisions for the selection of contractors, rankings, termination, etc. The effect is reinforced by the possibility of the generated and signed decision to be applied to the Buyer's profile, and simultaneously to be sent to all interested parties. This avoids the possibility of misuse of a not received decision and respectively limits the possibility of appealing an action/inaction of the contracting entity. The use of these two modules during the epidemic situation in the country was of particular importance. In practice, the commission's actions are possible in the first place, as the need for physical meeting is abolished and tenders are available in an entirely electronic environment.

The "Buyer's Profile" module creates a prerequisite for increasing transparency and trust in the system. Implementing electronic files, generating an electronic record and attaching all documents to the tender file in practice creates a single point of access to all information on a specific tender. Published documents contain time stamps, and the generated HASH ensures the impossibility of an unregulated change of the file content. The implementation of these functionalities makes forging documents and attaching them to the Buyer's profile at a later stage easily traceable. 
The creation of the new Public Procurement Portal optimizes how to search and find information in connection with the contracting process with intuitive design and architecture.

The "E-Contract" module closes the procurement cycle. The functionalities of the system allow, apart from the conclusion of a contract and the possibility for its management, the creation and publication of amendments and follow-up of the term for implementation of the contracts until their completion. There is an opportunity to create, sign and publish a contract/annex in an entirely electronic environment. Contracts can be created in a structured form and stored in the procurement record.

In connection with the management of public procurement contracts, a separate module "E-Contract Requests" was created. Users have the opportunity to create requests under a specific contract, send them to contractors and track their performance. The system calculates the residual value of the specific contract after each approved request and sends a notification message upon reaching $90 \%$ of the value. A link between module "E- Contract Requests" and module "E-Invoice" was realized. The "E-Payment" module was also developed. At this stage, the functionality serves the contracting entity by facilitating the creation of records in the payment system and the preparation of references in this regard. The actual payment is done outside the system, but the module provides a suitable basis for future optimization in this direction.

Three of the CAIS EPP modules are related to the performance of the control functions of the authorities with powers in the field. These are "External Control, carried out by PPA", "E-Appeal" and "Ex-post Control". The "E-Appeal" module allows interested parties to file a complaint directly through the system and to provide the Commission for Protection of Competition all the necessary information relating to the specific procurement by entirely electronic means. More specific is the implementation of the other two modules serving the needs of the control. This is necessary in view of the diverse practices of auditing authorities and methodological assistance. In view of this, the system provides the opportunity to create additional rights and roles to ensure access to the necessary documents of specific persons and for a specific period, while keeping a record of the actions carried out.

The "External Experts" module is built in the system as a natural continuation of the already existing and established practice for the use of persons with certain competences in specific areas in the preparation of procurement documents or as members of evaluation commissions. The system maintains a list of external experts, and the entry of data is made personally by experts, and organizations and associations can only provide recommendations for a specific expert on the list, but not make suggestions for their inclusion in it. 
CAIS EPP is linked to other registers in the country - Commercial Register, Register BULSTAT, Information System of the National Revenue Agency. Through official channels, data are generated in an open format to be published in the Open Data Portal and insures the opportunity to reuse them.

\section{Data on the public procurement market in the country following the obligation to apply CAIS EPP}

According to data from the Public Procurement Agency's Public Procurement Register, which has been in operation since 2004, the number of contracting entities in the country exceeds 6,700. This is the number of contracting entities that have started their contracts in the country through PPR since 2004.

With the introduction of the obligation to use CAIS EPP, which occurred on 1 January 2020, initially the system was used by a certain circle of 108 contracting entities and all others used the Public Procurement Register. The mandatory use of CAIS EPP starts with a relatively small number of contracting entities, which are among the most active and with the greatest experience in organizing and conducting public procurement. The entirely electronic awarding by different types of contracting entities requires different functionalities of the electronic system with different types of procedures. As a result, a gradual loading of the platform has been achieved and also checking its stability, reliability and performance. The aim was to reduce the potential risks of delaying the contracts and create conditions for a smooth transition to fully electronic procurement contracts during the subsequent use of the system by all contracting entities.

In general, pilot contracting entities may be divided into three groups. These are representatives of the central administration of executive power - the Council of Ministers, ministries, state commissions and agencies, executive agencies and other state bodies. The second group includes mayors of large municipalities, which have taken the lead in recent years in terms of the number of the awarded public procurements - Sofia Municipality, Plovdiv Municipality, Varna Municipality, Stara Zagora Municipality, Blagoevgrad Municipality, Burgas Municipality and Ruse Municipality. The latter group consists of sectoral contracting entities which are again selected among those with the highest experience, based on the number of contracts awarded. These are Kozloduy NPP SJSC, Maritsa East Mines SJSC, Maritsa East 2 TPP SJSC, Electric Energy System Operator SJSC and Port Infrastructure State Enterprise. For the other contracting entities, the obligation came into effect on 14 June 2020 or one month after measures were taken to deal with the epidemic situation in the country. 
The first procedure in the system was launched on 2 January 2020 by one of the largest sectoral contracting entities - Kozloduy NPP SJSC. This tender also reported a lot of activity by the business and nine offers were submitted.

For the period from the launch of the registration system until the end of May 2021, a total of 4,181 contracting entities were registered, including 4,074 public contracting entities and 107 sectoral contracting entities. The number of economic operators is 8,517 or these are 8,485 economic operators situated in Bulgaria and 32 abroad ( 24 within the EU and 8 outside the EU).

For the period from January 2020 to the end of May 2021, the total publications in the CAIS EPP are 17,476, and visits to the Public Procurement Portal from November 2019 to May 2021 are over 1.3 million.

In fact, for the whole 2020, the started procedures through CAIS EPP were 5,453 , with an estimated value of $6255216418.25 \mathrm{BGN}$ and contracts under the Public Procurement Law for 2020 were 4,604, amounting to 1129159379.12 BGN. During the specified period the number of tenders submitted through CAIS EPP was 27,095 or this is an average of 5 offers in a procedure.

The activity for the first quarter of 2021 is noticeable, where the procedures started through the system have been almost half of those in 2020 or a total of 2,857 with an estimated value of 4,268 $445492.20 \mathrm{BGN}$. For the same period the signed contracts under the Public Procurement Law were 2,542 with a value of 247446227.91 BGN. The number of offers submitted through CAIS EPP for the first quarter of 2021 is also high - 15,982 or on average 5.6 offers in a procedure.

In addition to procedures, interesting results are also observed in low-value tenders. Standardization of forms for low-value contracts in the system led to the high rate of award. For 2020 a total of 2,879 notices and invitations with an estimated value of 175024936.39 BGN were published. The number of the concluded contracts is 2,793 amounting to $111080789.21 \mathrm{BGN}$ and the submitted offers through CAIS EPP are 9,677 or this makes an average of 3.4 offers in a public procurement procedure.

For the first quarter of 2021, the data from the PPR of CAIS EPP show that 1,277 notices and invitations with an estimated value of 81959731.94 BGN have been published. For the same quarter, the number of contracts are 1,168 with the value of $50978955.15 \mathrm{BGN}$. The application of the system also leads to the high percentage of the offers, which for the period is 4,851 or 3.8 offers on average in public procurement.

\section{Conclusion}

What really happened? The first and most important benefit of the digitalization of the contracting process during the epidemic situation in a country is that it allows for continuity and smooth operation of the awarding process. The provision of an 
environment for conducting public procurement procedures entirely by electronic means has enabled all parties to work remotely. The development of modern information technologies has made access and management of public procurement possible from anywhere in the world, including through the use of mobile devices.

Bearing in mind that any change hides in itself risks and challenges, it should be noted that such were also available to the electronic award. It takes time to adopt the new digital reality, as well as to gain experience in implementing the new rules and changing the way we work. However, the benefits provided by electronic procurement far outweigh the risks of the transition.

Electronic procurement increases the publicity, transparency and predictability of the contracting process and hence the credibility of the system. The provision of a single point of access to information facilitates access to the market of public procurement. Furthermore, the actions of participants in the contracting process are no longer linked to the working hours of the administrations, but are possible at any time in a 24/7 mode. Increased access and rationalization of processes create prerequisites for higher levels of competition and stimulate the participation of SMEs in the process. Simplification of the contracting process saves time and resources, reduces the administrative burden and achieves better results, respectively. This meets the needs to increase the efficiency of public spending in the context of financial constraints, economic crisis and the apparent need to find new sources of economic growth.

The extension of the scope of beneficiaries of public resources should be added. Dropping the legal requirement for applicants/participants to provide a huge number of paper documents in an original or certified copy when submitting an offer is assessed as the first huge relief for the business and reduces the administrative burden. The elimination of a range of potential subjective circumstances shall be reported to remove a particular participant from a relevant procedure. In confirmation of the above, the use of electronic means saves the time needed to prepare an offer, and the document templates/structured data in the system are of key importance for the successful participation in tenders. In a pandemic, everything mentioned played a positive role in the country's economy by keeping the balance and allowing business flexibility in the working process and achieving efficiency and profit.

A particularly positive prospect of digitalization in the sector also reduces the opportunities for corrupt practices by eliminating the subjective factor. Moreover, digitalization provides a new type of comparative analysis opportunities in the course of procedures, which refers to reference values for similar supplies or services, and which can ensure data on weaknesses or ways of improving the process. This is a direct addressing of the problem of the "corruption-based" distribution of public resources, and the digitalization of the process is a 
mandatory measure to reduce the corruption risk in conducting procedures under the Public Procurement Law.

Despite the difficult economic and social months of 2020 and the beginning of 2021, Bulgaria successfully implemented the digitalization of the contracting process at all stages. Thus, in mid-2021 Bulgaria acquired a working electronic award system, which facilitates end users in their daily work on launching procedures, applying and participating in them, as well as providing higher levels of transparency in the process and minimizes the possibilities for data manipulation. The benefits of the introduction of the new electronic procurement system are visible to all consumers, including the general public, which is an important step today in ensuring transparency in spending public resources. Higher levels of competition, publicity and transparency, better accountability and standardization of the processes have been achieved while facilitating the access to the public procurement market in the country, reducing the administrative burden and transaction costs. All this leads to significant savings in funds and reduces the time to prepare a tender by the business and that for the conduct of the procedure by the contracting entities. Hence, automation of processes unleashes human potential, which can be used in solving other important issues of the contracting process - expediency, efficiency, continuity of the supply process, etc. The actions taken have a key and positive impact on the development of our economy in these difficult conditions, allowing work from a distance to be effective and efficient.

\section{References}

Европейска комисия. (2019). Доклад за България за 2019 г., включващ задълбочен преглед относно предотвратяването и коригирането на макроикономическите дисбаланси (Evropeyska komisia, 2019, Doklad za Bulgaria za 2019 g., vklyuchvasht zadalbochen pregled otnosno predotvratyavaneto i korigiraneto na makroikonomicheskite disbalansi) $\{\mathrm{COM}(2019) 150$ final $\}$, available at: https://ec.europa.eu/info/sites/info/files/file_import/2019european-semester-country-report-bulgaria_bg.pdf

European Commission. (n.d.). Public Procurement, Why public procurement is important, available at: https://ec.europa.eu/growth/single-market/publicprocurement_en

Decision № 108 of the Council of Ministers of 19.02.2015 on the selection of a model of platform for electronic procurement and completion of the implementation of a contract for services to support the implementation of a project between the Ministry of Economy, Energy and Tourism and the European Bank for Reconstruction and Development. 
Decree № 332 of the Council of Ministers of 13 December 2019 on the adoption of a timetable for use of the centralized electronic platform under Art. 39a, para. 1 of the Public Procurement Law.

Directive 2014/24/EU of the European Parliament and of the Council of 26 February 2014 on public procurement and repealing Directive 2004/18/EC.

Directive 2014/25/EU of the European Parliament and of the Council of 26 February 2014.

Pavlova, M. (2020). The advantages of the Dynamic Purchasing System in the context of the Bulgarian reality, Yearbook of UNWE, Issue 2, pp. 109-119.

Pavlova, M. (2015). Electronic Public Procurement as a Factor for Economic Development, Reports, Eleventh International Scientific Conference of Young Scientists, on the topic "Economics of Bulgaria and the European Union: Competitiveness and Innovation", December $15^{\text {th }}$, UNWE, Sofia.

Public Procurement Agency. (2014a). National Strategy for Development of the Sector Public Procurement in Bulgaria for the period $2014-2020$.

Public Procurement Agency. (2014b). Roadmap for Implementation of the Strategy for Development of e-Governance in the Republic of Bulgaria for the period $2014-2020$.

Public Procurement Law, in force from 15.04.2016. 